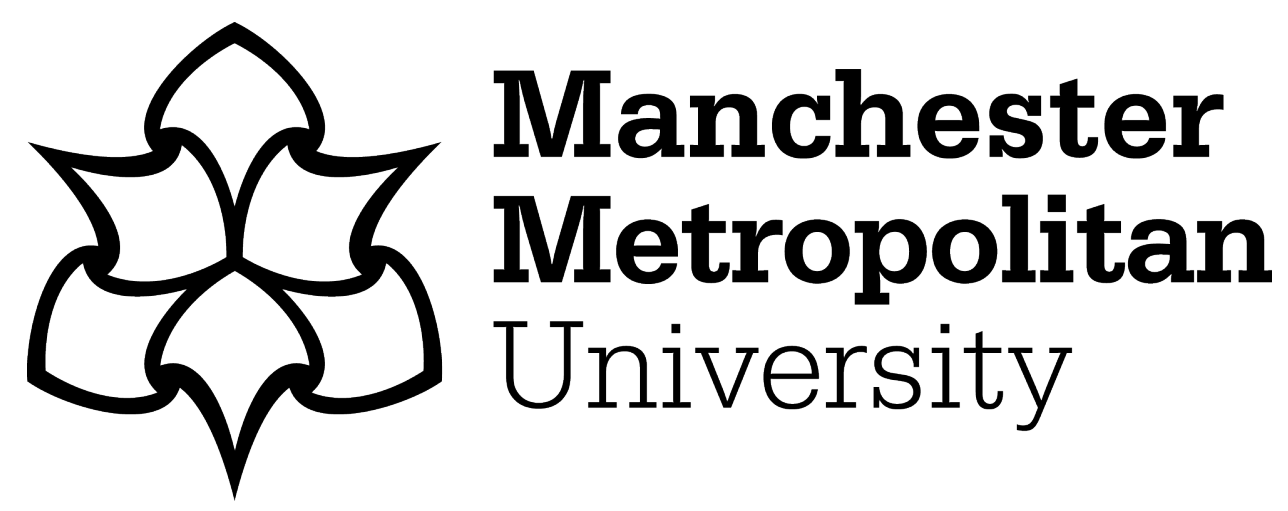

Bresnen, M, Hodgson, D, Bailey, S, Hyde, P and Hassard, J (2017) Mobilizing management knowledge in healthcare: Institutional imperatives and professional and organizational mediating effects. Management Learning, 48 (5). pp. 597-614. ISSN 1461-7307

Downloaded from: https://e-space.mmu.ac.uk/620626/

Publisher: SAGE Publications

DOI: https://doi.org/10.1177/1350507617718257

Please cite the published version 


\title{
Mobilizing management knowledge in healthcare: institutional imperatives and professional and organizational mediating effects
}

\author{
*Bresnen, M., Hodgson, D., Bailey, S., Hyde, P. and Hassard, J. \\ Alliance Manchester Business School, University of Manchester \\ *mike.bresnen@mbs.ac.uk
}

\begin{abstract}
Author Accepted Manuscript
Accepted 4 June 2017 by Management Learning and published on-line 12 July 2017.

To be cited as:

Bresnen, M., Hodgson, D., Bailey, S., Hyde, P. and Hassard, J. (2017) Mobilizing management knowledge in healthcare: institutional imperatives and professional and organizational mediating effects. Management Learning. Copyright @ 2017 (The Authors).
\end{abstract}

Full paper can be found at:

https://doi.org/10.1177/1350507617718257

\section{Acknowledgements}

This project was funded by the National Institute for Health Research Service Delivery and Organization (NIHR SDO) programme (project number 09/1002/29). The views and opinions expressed therein are those of the authors and do not necessarily reflect those of the SDO programme, NIHR, NHS or the Department of Health. 


\title{
Mobilizing management knowledge in healthcare: institutional imperatives and professional and organizational mediating effects
}

\begin{abstract}
Recent changes within UK healthcare have had dramatic consequences for management and put their capabilities firmly under the spotlight. Yet, despite extensive research on managers, comparatively little is known about how they acquire and apply their management knowledge, and how this is influenced by their professional background and organizational context. Drawing upon work that distinguishes between different forms of knowledge, managers' mobilization of management knowledge is examined in the light of recent changes in healthcare. Case study evidence is presented from diverse managerial groups across three types of hospital trust (acute, care and specialist). The analysis demonstrates the mediating effects of interactions between professional background and organizational context on knowledge mobilization, and highlights how current pressures on public services are reinforcing a reliance on existing management practices, creating enormous challenges for management learning in this sector.
\end{abstract}

\section{Keywords}

Management, knowledge, healthcare, hybrid managers 


\section{Introduction}

Change and innovation have been profound in recent years in many public sector institutions world-wide. In the UK public healthcare system, pressures have been put on the health service to improve efficiency and cost effectiveness as well as the organization and delivery of care (DH, 2010; Whitehead et al., 2010). Principal amongst the features of UK healthcare targeted have been managers and their capabilities (Hyde et al., 2016). Over the last decade, a series of government policies and institutional initiatives have led not only to major cuts in middle management capacity, but also challenged existing approaches to management and questioned the value of managerial capabilities and skills (King's Fund, 2011).

An important element of this critical examination of healthcare management is the longstanding recognition that supposedly 'leading-edge' management thinking does not translate easily into a healthcare context. Furthermore, it is clear there are major institutional and organizational barriers inhibiting flows of managerial knowledge and learning (Ferlie et al., 2015). Particular attention has been focused on the importance of clinicians in shaping management action (Llewellyn, 2001; Oborn et al., 2013), as well as tendencies towards a more 'inward-looking' approach to addressing management and organizational problems (McNulty, 2002). Yet, comparatively little is known about how healthcare managers mobilize and utilize management knowledge at the level of practice (Ferlie et al., 2012; Swan et al., 2016). While it is clear some codified systems of knowledge do appear to influence management thinking and action (Ferlie et al., 2015), evidence of their impact on practice is patchy, implicit and challenged (McCann et al., 2015; Hyde et al., 2016). Moreover, there is a tendency to disregard the variegated and contested nature of management knowledge as it 
applies to healthcare in favour of a simplified evidence/non-evidence dichotomy (Learmonth, 2008; Morrell and Learmonth, 2015).

There is considerable value, therefore, in developing more in-depth research into how healthcare managers acquire and apply knowledge - research which is sensitive to how different forms of knowledge may inter-relate to shape managerial thinking and practice (cf. Cook and Brown, 1999). Such research must take seriously the diversity within healthcare, the wide range of individuals engaged in managing, and also the large number of organizational types which deliver services (Buchanan, 2013). This paper seeks to examine these themes by exploring the mobilization and interaction of various forms of management knowledge in practice. It also considers how this relates to the organizational context of management action, as well as to managers' diverse backgrounds and experiences in different occupational communities of practice (Bate and Robert, 2002; Buchanan et al., 2007). It focuses particularly upon the knowledge base mobilized by 'hybrid' clinical-managers (Currie and White, 2012; Burgess and Currie, 2013) and how this relates to that of their socalled 'pure play’ counterparts (Buchanan, 2013).

\section{Management knowledge in healthcare in a context of change}

The economic downturn since 2008 has had a significant global effect on managers and management across both public and private spheres, with the impact of financial cuts and associated organizational change and restructuring falling particularly heavily on the public sector (Hyde et al., 2016). The impact upon those employed in middle management positions has been dramatic, particularly in healthcare. In the UK, not only have sharp decreases in 
government funding featured in 'austerity' plans, but legislative changes affecting the NHS have also had a profound effect.

In 2012, the UK government passed the Health and Social Care Act, which enacted the recommendations of a white paper proposing reducing management costs by $45 \%$ over four years (DH 2010). Although 'frontline' managerial positions were protected (to avoid public criticism), the act effectively delayered the NHS by cutting management numbers in secondary care institutions and abolishing several administrative organizational tiers dedicated to local and regional strategic planning (Whitehead et al., 2010). Other major changes included introducing more commercialism and competition through allowing 'any qualified provider' to bid for NHS service contracts (Hyde et al., 2016: 27). Further pressures on management came through the Five Year Forward Review, which proposed $£ 22$ billion efficiency savings by 2020 (NHS England, 2014). The impact on NHS managers has been a simultaneous intensification of work and transformation of roles, with managers still being expected to implement substantial organizational change in the face of continuous headcount reduction (Hyde et al., 2016). Given the unfavorable reputation middle managers have acquired in recent years (Brocklehurst et al., 2009), it is perhaps unsurprising there was relatively little critical public response to the proposed cuts in management, as this could be presented by policy-makers as reducing 'bureaucracy' to allow greater concentration of resources on front-line provision.

In this extremely challenging context, attention has been directed at the quality of healthcare management and the professional expertise and knowledge base available to and used by healthcare managers (King's Fund, 2011). For some time, healthcare management has been perceived as 'lagging behind' developments in (private sector) practice. In turn, such 
negative profiling has seen emphasis placed on the need for healthcare managers to mobilize supposedly 'leading edge' management thinking more effectively (Pollitt, 2013), as well as act in more innovative, financially-aware and entrepreneurial ways (Hyde et al., 2016). This has led to examination of the nature of managerial work, its professional basis and underpinning body of knowledge (Ferlie et al., 2012) - the space and time to develop new managerial capabilities becoming rarer just as these capabilities are in most demand.

As in other sectors, healthcare management has struggled to develop a distinct knowledge base based upon a clear-cut professional identity (Currie, 1997). Healthcare management is highly differentiated - involving not just general managers, but also clinical and nursing staff and extending across diverse specialisms and delivery modes (Buchanan et al., 2007). Furthermore, while healthcare management is sufficiently similar to management in other contexts to make generic principles and practices relevant, it is distinctive enough to make the application of generic management knowledge problematic (Currie and Suhomlinova, 2006). Indeed, healthcare management has its own institutional modus operandi, driven inter alia by distinctive clinical service operational demands, stringent regulatory requirements and close political and public scrutiny (Bevan and Hood, 2006).

Healthcare is also marked by a heavy reliance on hybrid managers (Llewellyn, 2001), with many management functions, at all levels, being delivered by clinicians and other health professionals (e.g. nurses). Particular attention has been directed towards understanding the consequences for healthcare management of the different orientations and logics of business and clinical managers (Currie, 1997, 2006; Llewellyn, 2001). Not only does clinical discourse impact substantially on determining what can be considered suitable and acceptable management knowledge (Davies and Harrison, 2003), it also plays an important role in 
shaping managerial knowledge and identity (von Knorring et al., 2016). Indeed, management initiatives in healthcare often cut across a multitude of clinical and other professional/occupational interests (Currie, 1997; Bate and Robert, 2002; Currie and Suhomlinova, 2006). Hybrid managers therefore play a crucial role in bridging relationships between managers and clinicians, as well brokering knowledge across boundaries in healthcare organizations (Currie, 2006; Currie and White, 2012; Burgess and Currie, 2013; McGivern et al., 2015). However, they face many challenges in doing so and are a diverse group with potentially distinct orientations to management (Currie and Croft, 2015; Kislov et al., 2016). McGivern et al. (2015), for example, make a useful distinction between 'willing' hybrids who are much more likely to embrace management; and 'incidental' hybrids who are much more likely to see management as an adjunct to their clinical professional role.

Despite the pivotal role of hybrid managers, research continues to suggest a subordination of managerial logics and identity to that of clinicians (Currie et al., 2009; von Knorring et al., 2016). Moreover, the management knowledge bases that hybrid managers and their pure play managerial counterparts mobilize often struggle to meet the baseline scientific requirements that underpin the hegemonic medical/clinical discourse in healthcare (Oborn et al., 2013). Developments in medical thinking that have emphasized the importance of 'evidence-based medicine' have prompted much speculation about the prospects for 'evidence-based management' in healthcare (Walshe and Rundall, 2001). However, management knowledge reflects a range of ontological and epistemological characteristics (Rousseau, 2006) and so reducing it to a 'unitary' system seriously misrepresents much of its pluralist and contested nature (Learmonth and Harding, 2006; Learmonth, 2008). Critically, it is argued that putting faith in evidence-based management - often inspired by a background in clinical training and 
research - can represent a substantial impediment to effective management learning (Morrell and Learmonth, 2015).

Important questions still remain therefore about the constitutive knowledge base of hybrid managers and their pure play counterparts at the level of management practice. Principal amongst these are: what forms of management knowledge do such managers have access to; how do they interpret and apply that management knowledge in practice; and how is this affected by their backgrounds (clinical, managerial, hybrid) as well as the (changing) contexts in which they act? While managers operate within a complex milieu of circulating management ideas and practices, it is evident that, even for pure play managers, there are challenges in harnessing and translating those ideas into practice (Ferlie et al., 2015). Moreover, pure play and hybrid managers are likely to have diverse orientations to management knowledge: ones shaped by the professional training and socialization associated with their particular (clinical and non-clinical) communities of practice (e.g. Bartunek, 2011).

The proliferation of ways of thinking and the wide range of tools and techniques constituting management knowledge pose challenges for categorizing forms and understanding how they are mobilized in healthcare. Recent thinking about forms of healthcare management knowledge has tended to reject the notion that knowledge is a commodity that can simply be transferred or translated into practice (Oborn et al., 2013). It has also questioned the narrow focus on knowledge utilization or exploitation (Nicolini et al., 2014; Swan et al., 2016). Instead, recent research has followed wider conceptual thinking in moving towards a more socialized understanding of the processes through which knowledge and learning are shaped 
by the professional communities of practice and the context within which managers act (Carlile, 2004; Burgess and Currie, 2013).

A basic distinction between tacit and explicit forms of knowledge (Nonaka and Takeuchi, 1995) allows some differentiation to be made between explicit, codified systems of knowledge (such as particular management tools and techniques) and forms of knowledge that are dependent on individual cognition/intuition (as gained through personal experience). At first hand, this appears to help us identify some of the main challenges of socialization, externalization and internalization involved in attempting to convert one form of knowledge into another for the purposes of knowledge sharing and creation (Nonaka and Takeuchi, 1995). Nevertheless, it provides only a very simplistic and questionable binary distinction (Tsoukas, 1996) - one that fails to lend itself to capturing the full range of forms of knowledge managers rely upon, or to appreciating the numerous and varied processes involved in knowledge mobilization (Gabbay and le May, 2004).

In contrast, practice-based views on knowledge offer useful insights into such aspects. Blackler (1995), for instance, categorizes knowledge types into five recurrent 'images' identified in the literature: knowledge embedded in technologies, rules and procedures; that embodied in the physical skill sets of individuals; that embrained in the intellectual abilities of individuals; that encoded in more abstract (management) knowledge, tools and techniques; and that encultured in the professional norms, values and practices of (institutionally legitimized or professionally accredited) managers. Cook and Brown (1999) go further by highlighting the generative processes that result when individual and collective forms of knowledge (found variously in explicit concepts, tacit skills, explicit stories and tacit 'genres') combine with processes of knowing that occur through practical action. This focus 
on how knowledge connects with, and is made sense of, in the context of management practice, recognizes that "these activities acquire particular shape and meaning from their organizational contexts" (1999: 390). This approach therefore presents a much more interpretive and socialized take on knowledge mobilization processes (cf. McNulty, 2002).

Here, we build on this socialized conception of knowledge mobilization to explore how managers relate to different forms of knowledge and how they seek to apply that knowledge to practice in order to help meet their management commitments and challenges, taking into account their varied backgrounds and diverse organizational settings. As such, an attempt is made to delve more deeply into the sources of knowledge that inform the collectivelyreinforced and internalized tacit guidelines or 'mindlines' of managers (Gabbay and le May, 2004). While these may be influenced by manager's distinct professional perspectives on forms of management knowledge, importantly they are also situated in the context in which managers act (Gabbay and le May, 2004; Burgess and Currie, 2013). Given current conditions within UK healthcare, this analysis highlights the growing contradiction between the logic of current institutional and organizational change and expectations increasingly placed on managers to engage with wider sources of managerial knowledge.

\section{Research methods}

This research on which this paper is based is derived from a study funded by the UK National Institute of Health Research (NIHR). The key question shaping the study was how managers learned, applied and shared management knowledge in a variety of healthcare contexts. The study aimed to elaborate on the role of communities of practice in the mobilization and utilization of management knowledge, and sought to understand challenges to the effective 
take-up and use of management knowledge at the individual and organizational level. The novelty of the approach lay in examining these management knowledge processes across a diverse range of managers and organizations.

Three hospital trusts, based in the same English region and representing quite different ranges of activity, participated. They were: a general hospital (Acute); a mental health and community services trust (Care); and a hospital providing specialist, tertiary care (Specialist). Within each trust/hospital, managers were selected on the basis of a framework that differentiated between three broad cohorts - clinical, general and functional (see Figure 1). Within each cohort, managers were purposively sampled across a range of operational and functional areas and selected for interview if they could be defined as middle managers by being positioned at least two levels up and two levels down the managerial hierarchy (McConville, 2006: 639).

\section{FIGURE 1 ABOUT HERE}

Semi-structured interviews (each conducted by at least two members of the research team) combined with observation of formal and informal events (from management meetings to training programmes) constituted the core methods of data collection. In total, 68 respondents were interviewed (some more than once) and 54 hours of observations were recorded (see Table 1 for a breakdown by trust and management cohort). Observational data were used to help 'ground' the analysis of management in practice, and also to provide a cross-check on accounts of management processes (e.g. training events and committee decision-making). 
Interviews were conducted in 2012-13, when some of the largest changes ever made to the NHS were being enacted. The timing of the research shaped the kind of data collected, with questions concerning change taking greater prominence.

All interviews were recorded and transcribed and field notes from direct observations taken either during or soon after an event. Interview schedules and subsequent coding were organized around five broad areas: career, knowledge, relationships, organization and change. Interview transcripts were coded independently by two members of the research team via NVivo software, using open coding techniques (Strauss and Corbin, 1998). Codes were then compared and discussed with a third member of the team to establish consistency in interpretation. These codes were then consolidated and structured around 5 broad first-order 'axial' codes (Locke, 1996) associated with organizational context, knowledge, networks, conceptions of management/leadership, and work identity/role. From this point, analysis proceeded in iterative inductive and deductive cycles, drawing upon literatures related to knowledge, identity and management/leadership to refine the coding structure and coded data (Gioia et al., 2012). We then compared coded data between the three case organizations and between the three cohorts of managers to identify patterns under each of the axial codes.

\section{Research findings}

Blackler's (1995) classification of knowledge types provided a shorthand way of referring to forms of knowledge emerging from the data during the coding and analysis process. We examine references to different knowledge types in the context of the organizational setting and with reference to the background of the manager interviewed (clinical, general or 
functional). The aim was not to engage in statistical generalization, although the structured sampling did reveal differences in emphasis which could be traced to organizational context and managerial identity. Rather, the analysis focuses on generalizations regarding how managerial background and organizational context appear to interact with different forms of managerial knowledge (Yin, 2014).

\section{Institutional pressures and management processes}

Given the pressures on managers described, it was not surprising there were strong expectations for meeting statutory reporting requirements. Principal amongst these were the institutional requirements on healthcare trusts to meet expected care standards in line with NHS regulatory bodies' performance targets. ${ }^{1}$ Meeting these requirements placed emphasis upon capturing and reporting performance information. To achieve this, institutionally-driven but locally-developed (or 'home grown') management systems, geared towards management reporting, dominated. Management meetings observed at the Acute and Care trusts, for example, shared a common agenda driven by the need to process, assess and report performance information (using standard metrics and visual representations through 'RAG' dashboards).

While these management processes might be traced to a more generic management/administrative knowledge base, it was clear they privileged management knowledge embedded in standard bureaucratic systems and processes (cf. Blackler, 1995). Consequently, trusts were not only predisposed towards processing performance information, but were also expected to develop and conform to more formal and standardized management systems and processes:

\footnotetext{
${ }^{1}$ For further information about NHS regulatory bodies and processes visit http://www.nhs.uk/NHSEngland/thenhs/healthregulators/Pages/health-watchdogs-explained.aspx
} 
The organization needs you to tick their boxes ... to understand their must-dos and their must-haves and their givens ... If you can pay attention to that and translate your activity in a comprehensible way, that can carry you a long way. (Laura, Service Manager, Care)

These demands were augmented by challenges that faced all trusts due to tensions between corporate attempts to standardize processes and practices and the more diverse, local approaches used by unit managers. The effect of these pressures and demands was to encourage a highly pragmatic approach to management problem-solving and decisionmaking. This was clearly manifested in the extensive information-gathering associated with meeting institutional and organizational requirements - reported in monthly meetings; and in the imperatives of day-to-day managerial work, in which a strong emphasis was placed upon operations management know-how, involving:

... having a knowledge of NHS targets; having a knowledge of internal targets: what they are and what we have to do to get there ... [Consultants] have their own targets to see new patients ... So you've got to have a good knowledge of [how] the consultants work, how they manage their patients and how they manage their clinics ... There's a lot of capacity work going on at the moment ... Have we got the capacity to do that and, if we haven't, what are we going to do about it? (Hannah, Service Manager, Specialist)

A consequence of this was the effective 'crowding out' of time and resources available for mobilizing wider sources of knowledge - including those delivered through training and 
professional development. Managers across the three trusts had access to local formal management training opportunities and most $(52=76 \%)$ reported they received some or a substantial amount of training. This applied to all managers at Acute and most functional managers; it was clinicians at the Care and Specialist trusts that received 'minimal' management training. Managers particularly approved of training that was practical and applied and/or which involved interpersonal skills development. However, training tended to focus on what were considered routine aspects of managerial work (such as health and safety or HR training), making it not only mundane for general managers, but also unattractive to clinical managers.

Even where training was available and appreciated, many complained of the difficulty in taking time out from busy schedules to undertake it and/or to reflect upon and apply their learning:

The biggest thing, in terms of the learning and development side of things ... is reflective time. We don't have anywhere near enough ... Three months goes by and you realize you've not looked backward once and learnt anything. (Greg, Associate Director, Acute)

An over-emphasis on immediate operational demands was seen by many as a major constraint upon the development of strategic and creative thinking, and tended to reinforce localized learning based on 'management by exception' problem solving. Managerial learning was clearly taking place, and this was helped by practical, applied training. But, it was as much about managers learning to cope without sufficient time and resources as it was 
about being able to develop new ways of working, given the 'normalized intensity' (McCann et al., 2008) that characterized day-to-day work.

\section{Financial management knowledge}

Not surprisingly, financial pressures also played an important part in shaping managerial discourse. While each of the trusts was significantly affected by sector-wide cuts in budgets and management capacity, the effects were particularly felt at Acute. At the Care and (especially) Specialist trust, the effects were less dramatic and, while pressures to improve efficiency were discussed by the interviewees, there were greater commercial opportunities for business development and growth.

What became apparent from those interviewed was that expertise in financial management was increasingly seen as important by managers and this was shaping perceptions and processes of managerial work:

The NHS does not live in a benign background any more ... Our managers have to figure out how to write bids or how to be in meetings with commissioners and come out with a good result; or what happens when you get an enormous budget cut you can do nothing about. (Kerry, Operations Manager, Care)

Given this perceived change in the environment facing managers, conscious steps were often needed to instill appropriate financial management knowledge:

We try and educate all managers ... Whether they're a nurse, clinician, an administrative manager. We hold budget training sessions three times a year that 
anyone can come to ... When we've got a new budget holder ... we'll sit with them, we'll talk them through what it is that they're going to have to do as part of their role. (Julie, Head of Finance, Specialist)

Driven in part by the efforts of specialists like Julie, financial management and commercial thinking had become a more normalized aspect of managerial work - although receptivity did vary between managers:

There's some basic finance principles I've never been trained on ... and yet I'm having to use them ... You go and talk to finance and they have to give you ... a couple of hours of their time. Fine, I understand how budgeting works within the [trust]. Tick that box. (Matthew, R\&D Business Manager, Specialist)

Enrolling clinical managers into more financial ways of thinking was seen as particularly difficult:

If you mention something like a business case to the average consultant ... they'll know they should know what it is, they'll know they should be doing it in practice. If you said: ... where do you start? I think, most of them would draw a bit of a blank. (Brian, Associate Medical Director, Acute)

Nevertheless, some clinical managers had already started to recognize the importance of financial/commercial know-how - albeit framing it in terms of meeting clinical needs: 
If there's a new service we're developing, the commissioners ... [will] come to me to give a very clinical view ... Managers generally are trying to trim things down and make them more efficient ... I come from the other side ... While acknowledging we have to recognize the problems ... we're not in an ideal world where you can give everything to a patient. (Robert, Clinical Director, Care)

Consequently, while there were differences between trusts in how financial pressures were affecting managerial work, there was much commonality in the importance attached to financial/commercial imperatives. The evidence of internalization, including amongst clinicians, and the use of strategies to try to embed financial thinking in (clinical) managers' work, illustrates how managers' embrained knowledge (cf. Blackler, 1995) was being increasingly shaped by the language and forms of representation associated with budgeting, profit/loss, return on investment, and the like.

\section{Clinical perspectives and management knowledge}

Managerial careers and job experiences varied considerably, but there were clear splits between: clinical and general managers, most of whom could be considered hybrid managers (mostly nurses, but also some medics); the small number of pure play general managers; and the (larger) group of functional managers. Indeed, most of the 68 managers interviewed $(42=62 \%)$ came from a clinical or care professional background -5 doctors, 23 nurses, 5 scientists, 7 allied health professionals (AHPs) and 2 social workers. That included all clinical managers, as well as all general managers at the Care trust $(83 \%$ of which were former nurses) and over half at the Acute and Specialist trusts (63\% and 56\% respectively were ex-nurses). It also included two functional managers. Most of the 42 clinical and 
general hybrid managers had at least one relevant medical or nursing professional qualification; the exceptions were the AHPs, social workers and some medical scientists.

Clinical experience was particularly prevalent amongst managers at the Care trust, where nurse hybrid managers predominated. It was also common, however, at all trusts and significantly influenced management thinking:

Having the clinical background has been a real advantage. Because you can see it's not just about a process, a management style, a service. You look at things in a very different perspective when you've been hands-on. You've been on that ward, you've delivered treatment, you've delivered patient care. (Becky, Service Manager, Specialist)

This combination of clinical or healthcare qualifications, combined with often considerable clinical experience, provided many hybrid general managers with understanding that enabled them not only to communicate well with their teams, but also to engage authoritatively and effectively with clinicians:

I've got the clinical ability to sit with people and say well, actually, I don't buy that, I disagree with that ... Somebody from a purely business background wouldn't be able to say that to a clinician across the table, because they wouldn't feel that they've got that experience or expertise to do it. (Glen, Integrated Governance Manager, Care)

Nevertheless, despite their clinical background, hybrid managers, particularly nurse managers in the clinically-prestigious Specialist trust, reported difficulties in establishing credibility, 
reflecting the recognized and pervasive status differential between nurses and doctors in healthcare (Currie and Croft, 2015). Often, exerting influence relied not just upon taking a clinical perspective, but augmenting that with other inter-personal skills. These might involve fairly obvious forms of persuasion - co-opting clinicians into decision-making, for example:

Sometimes I think the clinicians have got the answers; so it's actually good to listen to them because actually they're doing it day to day ... If they've come up with the idea then they're going to help push it forward. (Hugh, Operational Lead, Acute)

Elsewhere, it might involve the use of other forms of knowledge brokering activity to help enhance managerial legitimacy. For example:

The care pathway ... could just have been done by me and my operational manager ... [But] you absolutely need buy-in from the consultant ... You can't do that, without having my clinical lead with me, to demonstrate that we understand what we're talking about. (Hasin, Operations Manager, Care)

Whatever the approach taken, the inevitable consequence was some accommodation of clinical perspective:

Working with medics is interesting. I think the key to doing that successfully is being able to negotiate and communicate well with people and to ... see how you can adapt things so that you meet people's different professional background and models. It's compromising a lot. (Jocelyn, Service Manager, Care) 
Moreover, taking a clinical perspective was often accompanied by making sense of management through clinical epistemic practices. For example, diagnosis and prescription were used by some managers as ways of framing managerial problems and solutions:

The way we have practiced absolutely influences the way I work and perform as a manager ... I would meet a patient, assess them, and then have a conversation about what the treatment options are ... Those are fundamental principles I apply in my role now. So we assess a situation ... What is the problem? ... What are our options? Okay, how are we going to take this forward? ... We'll implement the change that we need to implement ... And is it better or not? (Melissa, Associate Director, Acute)

Such encultured clinical understandings (cf. Blackler, 1995) may have helped hybrid managers make sense of management and engage with clinicians. However, they also encouraged hybrid managers - already predisposed to clinical ways of thinking based upon a particular epistemology of knowledge (diagnostic and evidence based) - to continue to do so to create convincing and credible management arguments (cf. von Knorring et al., 2016).

\section{Exploiting management tools and techniques}

If hybrid managers faced the need to establish credibility, then the challenges facing pure play managers in gaining credibility and in embedding more encoded management ideas (cf. Blackler, 1995) into local practice were greater. Pure play managers expressed greater familiarity with, and faith in, management knowledge codified in generic methodologies and tools; as did functional specialists with expertise in areas such as project management. The number of advocates of more abstract management tools and techniques within this group 
was small. However, this was compensated for by the strength of commitment to particular ways of framing management problems. Emma offered a good example:

I love frameworks and tools and techniques. Although I don't want to be slavishly wedded to them, I like [that] way of making sense of things ... I suppose it's just the way my brain works. It helps me think things through if I can use some tool to start to work an issue through. (Emma, Head of Business Planning, Care)

There were several references made to attempts to import and apply Lean Thinking principles to the sector, particularly at the Acute trust. However, it was also clear the heyday of these initiatives had passed and application had been patchy due to significant problems in embedding the system practically. As a result, efforts to promote Lean Thinking had now gone 'under the radar'. As an advocate of such principles, Greg was aware of the problems of direct application, but convinced of the continuing benefits of using Lean Thinking to help teams reflect on alternative ways of working:

We had an all-day event yesterday with the new community teams ... about how we can amalgamate and transform these teams. And really what we did in was effectively Lean [Thinking], in the sense it was value stream mapping. We were going through, looking for elements of waste ... but it was never packaged as that. (Greg, Associate Director, Acute)

A similar preference for surreptitiously using standard management techniques to frame management problems was apparent in how others explained the use of techniques such as Process Mapping or Strategic Modeling. Again, Emma gave a good example: 
If you're doing a full developmental day with a team, then I would absolutely use some tools to help them through. But in terms of day to day management of my team ... it's probably far more intuitive. I'm not constantly ... doing a SWOT analysis of everything. (Emma, Head of Business Planning, Care)

Amongst 'willing' hybrid managers (cf. McGivern et al., 2015), there were nevertheless some clear examples of receptivity to more esoteric, codified management ideas - due to their perceived direct benefits for patient care:

I was keen to develop those modernization skills of Process Mapping, Lean, etc. And because of my nursing, clinical background, it felt like a really natural move, that it bridged knowledge of clinical processes plus developing better management processes and ways of delivering critical care. (Roxanne, Programme Manager, Acute)

Amongst 'incidental' hybrid managers, however, it was more common to find a pragmatic and selective use of management knowledge to address particular management problems. Ramesh (Clinical Director, Acute), for example, referred to the "little tit-bits" of knowledge he had picked up from training. Others similarly showed receptivity to new management ideas, while also emphasizing the less systemic nature of their management learning:

I've been on lots of management courses over the years ... and you do get snippets here and there. It's hard to know what goes into your subconscious. I've certainly been in lots of meetings where I've thought, wow, that's brilliant ... But then I've 
gone back to my normal work and behaved in more or less the same way ... Most of it is muddling your way through a problem and finding a solution that works. (Brian, Associate Medical Director, Acute)

The principal challenge for proselytizers of codified management knowledge within each trust was therefore to link their ideas more subtly with the needs of receptive hybrid managers in ways that would help them 'muddle through'. Emma, who depicted this as "translating that into a story they recognize" went on to stress the facilitation involved in:

... work[ing] with managers and clinicians in services, looking at the pathways, looking at the processes, helping them achieve the outcomes - because often they know the answers but don't know how to make it happen. (Emma, Head of Business Planning, Care)

At the same time, it was clear again that what was important was not simply the translation of meaning of new management ideas, but also their negotiated transformation in and through practice to meet clinical context and needs (cf. Carlile, 2004):

When they are talking about service redesign and the things that are really important to them, I think you do have to have some clinical input into that ... Because otherwise the thing that you think is going to be the best, most efficient and most effective way to go actually won't work because clinically it's not sound. (Elena, Service Manager, Care) 
Overall, there were major impediments to the application of codified systems of management knowledge - not simply due to problems with their suitability, but also with their acceptability (cf. McCann et al., 2015). Even those managers who were keen to promote different ways of thinking were self-conscious and self-effacing in their attempts to do so. Nevertheless, managers continued to find value in using such forms of knowledge to help facilitate analysis of local strategic and operational needs.

\section{Experiential and social learning}

This more subtle and intuitive approach to acquiring and using management knowledge was accentuated further by the observation that, for the most part, learning and the application of management knowledge was seen to be much more personally embodied (cf. Blackler, 1995) in managers' tacit skills, as well as being highly practically-focused and socially situated:

You can use whatever methodology you want, but at the end of the day, you're sitting there talking to people, trying to understand why they're doing what they're doing, and asking them to reflect and consider why they might want to do something differently. (Ross, Service Manager, Care)

Although one in four managers possessed foundational management knowledge in the form of management educational qualifications (usually PG Diploma or MSc/MBA and mainly amongst functional managers), these were far less prevalent across the sample than clinical or health-related qualifications. Generic management abilities that were most often emphasized as important to the job (e.g. interpersonal skills) were commonly presumed to be developed through experience and training. However, despite the importance attached by some managers to training, virtually every one interviewed put a stronger emphasis upon the 
importance of experiential learning as the basis for their accumulation of management knowledge. The following quote was typical of this privileging of on-the-job learning over taught management knowledge:

I think I've learned more on the job than anywhere else ... There are times you are managing the situation and you think, now what did I learn on that management course? And actually it's very difficult to use that ... It would be great to have something that could ... help you quickly with all these skills. (Robert, Clinical Director, Care)

An important aspect of experience was also the social learning that occurred. Formally, mentoring and coaching relationships with senior colleagues were important. Informally, managers often learned implicitly from each other - through direct observation and conscious role modeling. In some instances, these social experiences prompted managers to reflect on their managerial approach by contrasting it with an alternative more 'businesslike' ideal:

My manager is a real business manager. She's got a real business head on her, and it's interesting to learn from her ... She does think completely differently to me, but I think we actually complement each other quite well. I've learnt an awful lot from her. (Belinda, Therapies Manager, Acute)

However, the overwhelming emphasis in the interviews was upon the importance attached to social learning and learning by doing that tended to reinforce and reproduce existing ways of managing and accepted forms of knowing. In the training sessions we observed for middle managers at the Care trust, for example, leadership concepts were introduced, but managers 
clearly valued more the opportunities to interact with their colleagues and to share experiences of how to deal with leadership challenges they faced in their work. In other words, it was the strong ties used to share tacit understandings in familiar settings that tended to be most highly valued.

\section{Discussion}

Through this analysis, we have considered various ways in which healthcare managers engage with management knowledge and used the five 'images' of knowledge outlined by Blackler (1995) to highlight: the strong influence of knowledge embedded in local reporting rules and procedures; the growing importance of embrained financial expertise in the knowledge base of individuals; the continued strong influence of encultured clinical norms, values and practices, particularly amongst hybrid managers; a more limited and guarded engagement with encoded management tools and techniques; and a widespread valorization of embodied expertise and socialized, experiential learning. Of course, managers engaged with these multiple, inter-related forms of knowledge in various ways to shape their individual thinking and practice (cf. Gabbay and le May, 2004). However, understanding how these affected the managers interviewed also required a grasp of their varied professional backgrounds, as well as an understanding of the specificities of each organizational context, as well as the interaction between the two. Not only were these important mediating factors influencing knowledge mobilization, they also suggested serious obstacles to hopes of improving management learning and implementing new management knowledge in healthcare.

First, it is clear that institutional statutory reporting requirements played a major part in shaping orientations to management knowledge across all three trusts, encouraging typical 
bureaucratic methods of reporting that also converged with organizational efforts to promote greater standardization and formalization of process. The net effect was not only to narrow managerial attention to flows of performance management information and immediate operational concerns, but also to reinforce the primacy of 'home grown' management knowledge embedded in existing systems and practices. This left comparatively little time and space for training and reflection and limited the motivation to learn from alternative forms of management knowledge.

Second, financial management knowledge and expertise was becoming an increasingly important component of managerial work and having a major effect upon managerial agendas and 'embrained' knowledge (cf. Power and Laughlin, 1992). Although this took a different form across the trusts, there was some commonality in the extent to which financial expertise had become privileged and was internalized amongst functional and hybrid general managers. In contrast, despite some acceptance on their part, it continued to be a struggle to encourage clinical managers to think financially/commercially.

Third, as might be expected given inter-professional power relations in healthcare, clinical experience had a powerful effect in helping managers make sense of their management role and in brokering relationships with clinicians (cf. Currie and White, 2012; Burgess and Curries, 2013). Managers' relational skills were of course important in helping bridge the divide between managers and clinicians. However, these crucially built upon the 'encultured' understandings that clinical experience gave rise to and which enhanced hybrid managers' credibility - allowing them to move from one perspective/role (managerial) to another (clinical). Conversely, this hybrid capability clearly distorted how those managers interpreted 
and used management knowledge, by aligning it directly with their preferred clinical epistemologies (cf. von Knorring et al., 2016).

Fourth, there were clear limits to the extent to which other, more external, esoteric and encoded systems of knowledge were adopted or adapted. Codified management tools and techniques were not uncommon and some managers were keen to promote them. However, it was not simply that there were challenges in translating them into a healthcare context - due to differences in meaning and suitability - there were also major impediments to their spread - due to transformations in practice that were required for them to be accepted (cf. Carlile, 2004) and continuing questions about their validity and evidence base (cf. Morrell and Learmonth, 2015). Nevertheless, managers clearly found value in using such systems of knowledge surreptitiously, in order to help teams make sense of local strategic or operational options and constraints. As such, through management reflection, they still played an important generative role in promoting alternative ways of thinking (cf. Cook and Brown, 1999).

Fifth, the management knowledge most prized by managers was that gained from experience, and a strong emphasis was placed on more socialized and experiential forms of learning. Drawing recurrently upon strong social ties and personal knowledge bases may have enabled managers to deal, in very practical ways, with the problems and issues they faced. In other words, it encouraged the direct application of acquired skills and tacit understandings (or extrapolation of past learning) to the solution of immediate operational problems. However, there was also a downside - in the effects that such 'embodied' knowledge had in reproducing existing and accepted, 'tried and tested', ways of working. 
Taking these points together, the findings suggest that managers' mobilization of knowledge within (and between) healthcare trusts is not exclusively a function of professional orientations and backgrounds, or a consequence of contextual constraints that enable and inhibit flows of different sources and types of information, but rather a phenomenon that is informed by, and influences, both. It is widely recognized that there are obstacles to the direct translation of encoded forms of knowledge into practice (Ferlie et al., 2015) and that managerial 'mindlines' (Gabbay and le May, 2004) are strongly influenced by encultured professional understandings and embodied experience mediated by situated practice (cf. Carlile, 2004; Bartunek, 2011; Burgess and Currie, 2013). However, differentiating between types of manager and the contexts in which they act illuminates the more complex ways in which knowledge flows. It serves to identify, for example, systematic differences in the receptivity and strength of attachment to different sources and forms of knowledge between groups. In addition, it also reveals the contrasting opportunities available to these managerial groups when they seek to mobilize these forms of knowledge and instantiate their particular 'management thinking' in practice. To illustrate, we can compare the accounts of two types of general manager: hybrid and pure play.

Hybrid managers, who straddled the clinical-managerial divide (Llewellyn, 2001), generally took recourse to clinical experience and a clinical perspective in terms of dominant sources of meaning. However, they varied in the ways they engaged with management knowledge. Of these hybrids, those fitting the description of 'willing' (McGovern et al., 2015) appeared to ground their knowledge of management practices in ways that, while privileging clinical care, also readily accepted the value and plausibility of service improvement. Those characterized as 'incidental' hybrids were more distanced from management practice due to their strong and enduring clinical identity. Nevertheless, even these managers were at times 
able to appreciate the value of abstract management knowledge - albeit knowledge framed in less systemic and more clinical terms. In both cases, institutional and organizational imperatives created the need to respond by privileging more embedded forms of management knowledge. However, they also created such overwhelming pressure that it became hard for managers to do anything other than respond to immediate, mandatory and practical demands.

For pure play managers, whose receptivity to abstract management knowledge was stronger, the challenge became one of framing managerial tools and techniques in ways that made sense to their clinical and hybrid colleagues, and which acknowledged their frames of reference and the conditions they faced. The direct confrontation to clinical context and clinical identity implicit in early attempts to implement codified systems had now given way to much more subtle and socialized ways of instilling radical thinking about plausible process improvement. However for those managers too, their take on management knowledge was not only influenced by the need for clinical credibility, it was also conditioned by contextual pressures. In other words, clinical credibility and/or financial/institutional imperatives were the keys to them establishing influence and imparting management knowledge. The overall effect, then, was an inevitable distortion of management knowledge in its translation into healthcare management practice.

A more nuanced understanding of the flow of management knowledge in healthcare thus emerges when one takes into account the different professional backgrounds that informed managers' approaches to management in conjunction with differences in the organizational contexts in which they were acting. With regard to context, differences that seemed significantly to affect orientations to management knowledge were in the propensity for trusts to default to bureaucratic systems; in the nature and impact of financial and commercial 
imperatives; and in the relationships between hybrid and pure play managers. Where reporting systems and standard procedures were more developed, financial pressures more acute, and there was greater a differentiation between pure and hybrid managers (as at Acute), this appeared to heighten the challenges facing managers in mobilizing more abstract and less embedded management knowledge - compared with situations where processes were less standardized, commercial opportunities co-existed with financial pressures and hybrid managers were more ubiquitous (as at Care).

As some of these tendencies, such as financial pressures, increasing commercial imperatives and tighter bureaucratic monitoring, become more prevalent across the NHS, we can expect challenges in mobilizing alternative sources of management knowledge to intensify. This suggests a possibly greater divergence emerging than policy makers and institutional bodies might think between espoused theories surrounding professionalism in healthcare management and the theories actually used by managers faced with the daily agenda of pressing operational demands.

\section{Conclusion}

In light of calls for more effective mobilization of management knowledge in the field of healthcare, this paper has examined how managers in the NHS relate to different sources and forms of knowledge, drawing upon a socialized conception of knowledge mobilization. The study shows that specific organizational context and individual managerial background interact to inform how managers engage with particular forms of management knowledge, with clear implications for how this tends, on the whole, to reinforce existing management practice. In exploring the effects in different contexts of statutory reporting requirements, 
financial management concerns, clinical dominance, codified management methodologies and a deep faith in experiential learning, we have traced some of the implications and challenges which arise for different kinds of healthcare manager, with particular reference to the implications for hybrid and pure play managers. The combined effect is a profound challenge to effective knowledge mobilization, particularly given the pressures currently facing healthcare systems in general, and the NHS in particular. More research is needed to examine these tensions and their effects on managers if the aim is to understand better the major influences on managerial knowledge mobilization in healthcare. However, an important start has been made here in highlighting the multifarious nature of healthcare management knowledge and the mediating effect of professional and organizational circumstances on its mobilization.

\section{References}

Bartunek, J. M. (2011) Intergroup relationships and quality improvement in healthcare. $B M J$ Qual Saf 20(Suppl 1):i62-i66.

Bate P and Robert G (2002) Knowledge management and communities of practice in the private sector: lessons for modernizing the National Health Service in England and Wales. Public Administration, 80(4): 643-663.

Bevan G and Hood C (2006) What's measured is what matters: targets and gaming in the English public health care system. Public Administration, 84(3): 517-538. 
Blackler F (1995) Knowledge, knowledge work and organizations: an overview and interpretation. Organization Studies, 16(6): 1021-46.

Brocklehurst M, Grey C and Sturdy A (2009) Management: the work that dare not speak its name. Management Learning, 41(1): 7-19.

Buchanan D. (2013). Pure plays and hybrids: acute trusts management profile and capacity. Journal of Health Services Research \& Policy, 18(2), 90-97.

Buchanan D, Addicott R, Fitzgerald L, Ferlie E and Baeza J (2007) Nobody in charge: distributed change agency in healthcare. Human Relations, 60(7): 1065-1090.

Burgess N and Currie G (2013) The knowledge brokering role of the hybrid middle level manager: the case of healthcare. British Journal of Management, 24: S132-S142.

Carlile P (2004) Transferring, translating, and transforming: an integrative framework for managing knowledge across boundaries. Organization Science, 15(5): 555-68.

Cook S and Brown JS (1999) Bridging epistemologies: the generative dance between organizational knowledge and organizational knowing. Organization Science, 10(4): 381400.

Currie G (1997) Contested terrain: the incomplete closure of managerialism in the health service. Health Manpower Management, 23(4): 123-132. 
Currie G (2006) Reluctant but resourceful middle managers: the case of nurses in the NHS. Journal of Nursing Management, 14: 5-12.

Currie G and Croft C (2015) Examining hybrid nurse managers as a case of identity transition in healthcare: developing a balanced research agenda. Work, Employment and Society, 29(5), $855-65$.

Currie G, Finn R and Martin G (2009) Professional competition and modernizing the clinical workforce in the NHS. Work, Employment and Society, 23(2): 267-84.

Currie G and Suhomlinova O (2006) The impact of institutional forces upon knowledge sharing in the UK NHS: the triumph of professional power and the inconsistency of policy. Public Administration, 84(1): 1-30.

Currie G. and White L. (2012). Inter-professional barriers and knowledge brokering in an organizational context: The case of healthcare. Organization Studies, 33(10): 1333-1361.

Davies HTO and Harrison S (2003) Trends in doctor manager relationships. British Medical Journal, 326: 646-649.

DH (2010) Equity and excellence: liberating the NHS. London: Department of Health.

Ferlie E, Crilly T and Jashapara A (2012) Knowledge mobilization in healthcare: a critical review. Social Science and Medicine, 74(8): 1297-1304. 
Ferlie E, Ledger J, Dopson S, Fischer MD, Fitzgerald L, McGivern G and Bennett C (2015) The political economy of management knowledge: management texts in English healthcare organizations. Public Administration 94(1): 185-203.

Gabbay, J. and le May, A. (2004) Evidence based guidelines or collectively constructed 'mindlines'? Ethnographic study of knowledge management in primary care. BMJ 329.

Gioia DA, Corley KG and Hamilton AL. (2012) Seeking qualitative rigor in inductive research: notes on the Gioia methodology. Organisational Research Methods, 16 (1): 15-31.

Hyde P, Granter E, Hassard J and McCann L (2016) Deconstructing the welfare state: Managing healthcare in the age of reform. London: Routledge

Kings Fund (2011) The future of leadership and management in the NHS: No More Heroes. London: The Kings Fund.

Kislov, R., Hodgson, D. and Boaden, R. (2016) Professionals as knowledge brokers: The limits of authority in healthcare collaboration. Public Administration, 94(2), 472-89.

von Knorring M, Alexanderson K, Eliasson, A. (2016) Healthcare managers' construction of the manager role in relation to the medical profession. Journal of Health Organization and Management, 39(3), 421-440.

Learmonth M. (2008) Evidence-based management: a backlash against pluralism in organizational studies? Organization, 15(2): 283-291. 
Learmonth M. and Harding N. (2006) Evidence-based Management: the very idea. Public Administration, 84(2): 245-66.

Llewellyn S. (2001). 'Two-way windows': Clinicians as medical managers. Organization Studies, 22(4), 593-623.

Locke K. 1996. 'Rewriting the discovery of grounded theory after 25 Years?' Journal of Management Inquiry, 5(3): 239-45.

McCann L, Morris J and Hassard J (2008) Normalized intensity: the new labour process of middle management. Journal of Management Studies, 45(2): 343-371.

McCann L, Hassard J, Granter E and Hyde P (2015) Casting the lean spell: the promotion, dilution and erosion of lean management in the NHS. Human Relations, 68(10): 1557-1577.

McConville, T. (2006) Devolved HRM responsibilities, middle-managers and role dissonance. Personnel Review, 35(6), 637-653.

McGivern G, Currie G, Ferlie E, Fitzgerald L and Waring J (2015) Hybrid managerprofessionals' identity work: the maintenance and hybridization of professionalism in managerial contexts. Public Administration, 93(2): 412-432.

McNulty T (2002) Reengineering as knowledge management: a case of change in UK healthcare. Management Learning, 33(4): 439-458. 
Morrell K and Learmonth M. (2015). Against Evidence-Based Management, for Management Learning. Academy of Management Learning \& Education 14(4): 520-33.

Nicolini D, Powell J, and Korica M. (2014) Keeping knowledgeable: How NHS Chief Executives mobilise knowledge and information in their daily work. Health Services and Delivery Research, 2(26)

NHS England (2014) Five year forward view. London: NHS England.

Nonaka I and Takeuchi I (1995) The knowledge creating organization. Oxford: Oxford University Press.

Oborn E, Barrett M and Racko G (2013) Knowledge translation in healthcare. Journal of Health Organization and Management, 27(4): 412-431.

Pollitt C (2013) The evolving narratives of public management reform. Public Management Review, 15(6): 899-922.

Power M and Laughlin, R (1992) Critical theory and accounting. In M Alvesson and H. Willmott (eds.) Critical management studies. London: Sage, pp. 113-35.

Rousseau DM (2006) Is there such a thing as 'evidence-based management'? Academy of Management Review, 31(2): 256-269. 
Strauss A and Corbin J (1998) Basics of qualitative research: techniques and procedures for developing grounded theory. Thousand Oaks, CA: Sage.

Swan J, Newell S and Nicolini D (2016) (eds.) Mobilizing knowledge in healthcare: challenges for management and organization. Oxford: Oxford University Press.

Tsoukas H (1996) The firm as a distributed knowledge system: a constructionist approach. Strategic Management Journal, 17 (Winter): 11-25.

Walshe K and Rundall TG (2001) Evidence-based management: from theory to practice in health care. Millbank Quarterly, 79(3): 429-457.

Whitehead M, Hanratty B and Popay J (2010) NHS reform: untried remedies for misdiagnosed problems? The Lancet, 6763(10): 231-7.

Yin, R. K. (2014) Case study research: design and methods. Sage: London. 
Figure 1 Management selection framework

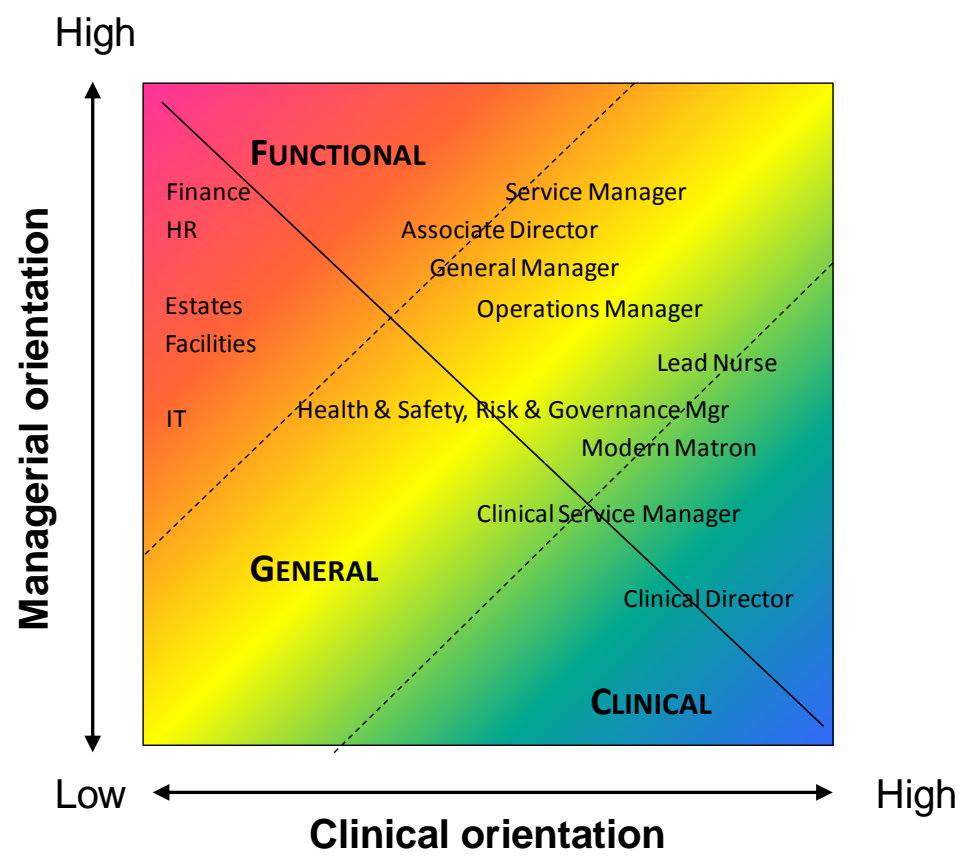


Table 1 Interviewees by management group and by trust

\begin{tabular}{|l|l|l|l|l|l|} 
& Clinical & Functional & General & Total & Total \\
\hline managers & managers & managers & participants & interviews \\
\hline Care Trust & 5 & 7 & 8 & 20 & 22 \\
\hline Specialist Trust & 6 & 6 & 12 & 25 & 33 \\
\hline Total & 18 & 8 & 9 & 23 & 30 \\
\hline
\end{tabular}

